\title{
Oscillatory hierarchy in a network of leaky integrate- and-fire neurons with short-term plasticity
}

Timothee Leleu*, Kazuyuki Aihara

From Twenty Second Annual Computational Neuroscience Meeting: CNS*2013

Paris, France. 13-18 July 2013

Cross-frequency couplings between oscillatory modes have been observed in cortical and hippocampal local field potentials recorded from the brains of rodents, primates[1] and humans. Multi-unit activity recordings have shown that the highest amplitude of gamma and theta oscillations occur at the rising positive going part of theta and delta oscillations, respectively[1]. We show that a network of leaky integrate-and-fire neurons with short term plasticity between pyramidal cells and interneurons can exhibit a similar oscillatory hierarchy (see
(A)

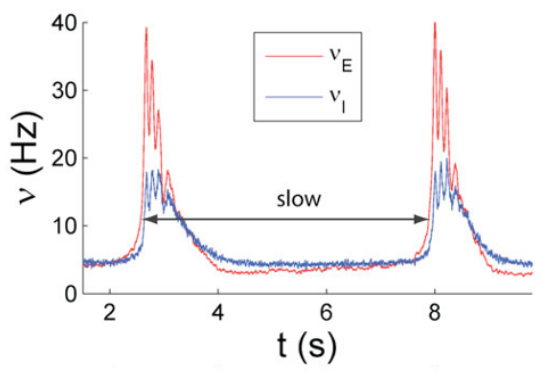

(C)

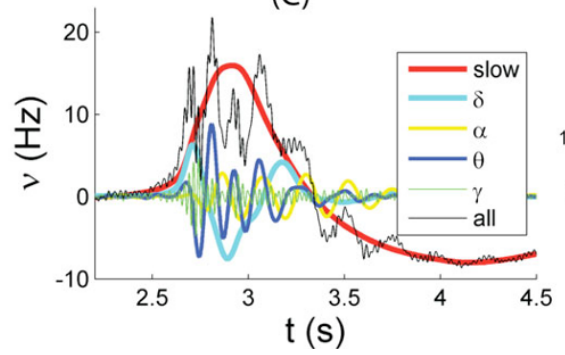

(B1)

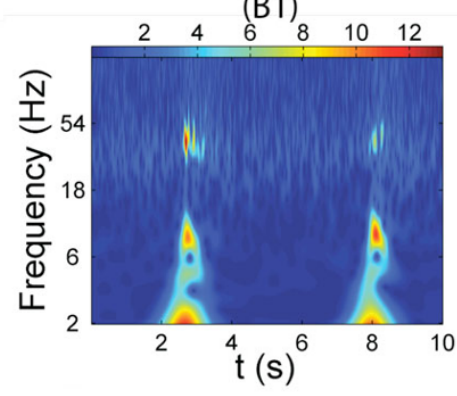

(D1)

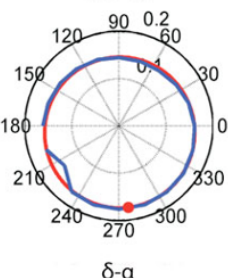

$\delta-a$
(D2)

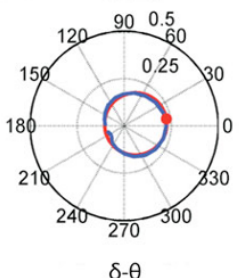

(B2)

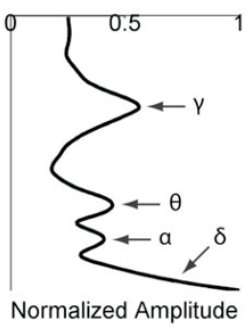

(D3)

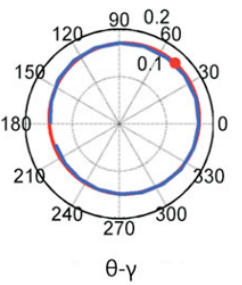

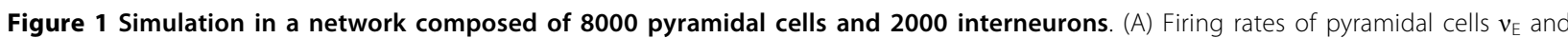
interneurons $v_{l}$ in red and blue, respectively, smoothen within a window of $25 \mathrm{~ms}$ duration. The frequency of slow oscillations is approximately $0.2 \mathrm{~Hz}$. (B1) Continuous wavelet transform of the firing rate $v_{\mid}$using Morlet wavelets. The color scale represents the energy for each coefficient of the wavelet decomposition (arbitrary scale). (B2) Normalized cumulated energy for frequencies shown in (B1). (C) Firing rate after applying a band pass filter around frequencies corresponding to slow, $\delta, \alpha, \theta$, and $\gamma$, respectively. (D1-D3) Cross-frequency coupling between two oscillatory modes $f_{1}$ and $f_{2}$ represented in polar coordinates. Radius and angle are the normalized average amplitude of $f_{2}$ and phase of $f_{1}$, respectively, obtained from the wavelet decomposition (method adapted from [1]). The blue line is the distribution calculated from the simulation of leaky integrate-and-fire neurons. The red line is the fitted von Mises distribution and red dot the phase of $f_{1}$ corresponding to the maximal average amplitude of $f_{2}$. (D1) $f_{1}=\delta, f_{2}=\alpha$. (D2) $f_{1}=\delta, f_{2}=\theta$. (D3) $f_{1}=\theta, f_{2}=\gamma$.

Institute of Industrial Science, The University of Tokyo, 4-6-1 Komaba,

Meguro-ku, Tokyo 153-8505, Japan

() Biomed Central

(c) 2013 Leleu and Aihara; licensee BioMed Central Ltd. This is an Open Access article distributed under the terms of the Creative Commons Attribution License (http://creativecommons.org/licenses/by/2.0), which permits unrestricted use, distribution, and reproduction in any medium, provided the original work is properly cited. 
Figure 1). Moreover, the network exhibits alpha oscillations which amplitude is modulated by the phase of delta oscillations. There is no phase-amplitude coupling between alpha and theta. Finally, these oscillations are nested in a slower $0.2 \mathrm{~Hz}$ oscillation. We study the mechanisms of these oscillatory patterns reminiscent of spontaneous cortical activity[2].

\section{Acknowledgements}

This research is supported by the the Aihara Innovative Mathematical Modelling Project, the Japan Society for the Promotion of Science (JSPS) through the "Funding Program for World-Leading Innovative R\&D on Science and Technology (FIRST Program)," initiated by the Council for Science and Technology Policy (CSTP).

Published: 8 July 2013

\section{References}

1. Lakatos $P$, et al: An oscillatory hierarchy controlling neuronal excitability and stimulus processing in the auditory cortex. J Neurophysiol 2005, 94(3):1904-11.

2. A Luczak, $P$ Bartho: Consistent sequential activity across diverse forms of UP states under ketamine anesthesia. Eur J Neurosci 2012, 36(6):2830-8.

\section{doi:10.1186/1471-2202-14-S1-P5}

Cite this article as: Leleu and Aihara: Oscillatory hierarchy in a network of leaky integrate-and-fire neurons with short-term plasticity. BMC Neuroscience 2013 14(Suppl 1):P5.

\section{Submit your next manuscript to BioMed Central} and take full advantage of:

- Convenient online submission

- Thorough peer review

- No space constraints or color figure charges

- Immediate publication on acceptance

- Inclusion in PubMed, CAS, Scopus and Google Scholar

- Research which is freely available for redistribution

Submit your manuscript at www.biomedcentral.com/submit 